\title{
Poll reveals backing for xenotransplants
}

[PARIS] More than three-quarters of the US public would consider a xenotransplant the transplant of an animal organ into a human — for a loved one "if the organ or tissue was not available from a human", according to a poll carried out on behalf of the US National Kidney Foundation (NKF). Only 2 to 5 per cent would completely rule out a xenotransplant in a life-or-death situation (see Briefing, page 320).

But widespread ambivalence and ignorance about the subject was revealed elsewhere in the poll, which was carried out by the market research company Southeastern Institute of Research, based in Richmond, Virginia. Although two-thirds of the 1,200 people polled think that xenotransplantation research should continue, more than three-quarters had only "heard a little" about xenotransplantation, and only 15 per cent had "heard a lot".

Opposition to xenotransplantation was strongest among the best informed. But onequarter of those strongly opposed to xenotransplantation research, and half of those who had never heard of it, would still consider a xenotransplant if no alternative were available.

The poll revealed a marked difference in the issues of most concern to the public and to scientists. Twenty-seven per cent were concerned about organ compatibility, but only 13 per cent about risks from infectious diseases, the major concern among scientists (although more than three-quarters said that learning more about disease risks could change their feelings about xenotransplants).

Respondents preferred baboons or chimpanzees as donors rather than pigs, whereas

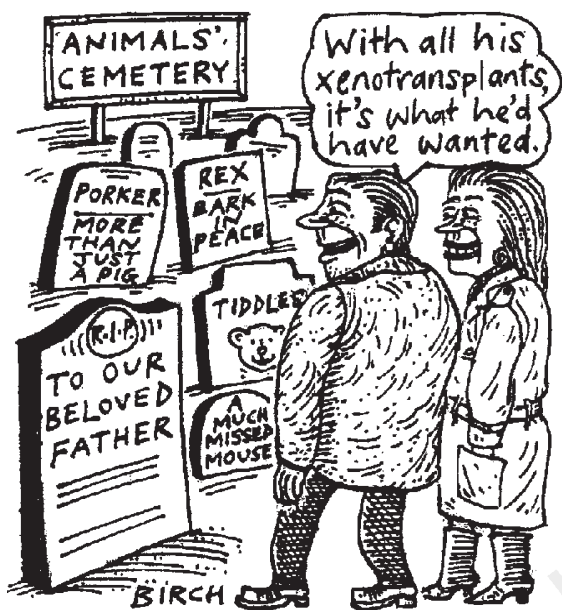

non-human primates are widely considered unsuitable and more risky by xenotransplant scientists (see page 324).

Polls of public attitudes on xenotransplantation need to be interpreted with considerable caution, says Abdullah Daar, a transplant surgeon at the Sultan Quaboos University in the Sultanate of Oman, and chairman of the xenotransplantation advisory committee set up last year by the World Health Organization. Daar points out that, although many polls have shown wide public support for xenotransplantation research, they fail to distinguish between research and clinical trials.

"How xenotransplantation is 'sold' to the public is likely to influence the response," says Daar. Responses will differ depending on whether xenotransplantation is billed "as a 'last resort' or as the 'best option'”. Public attitudes could also change quickly, says Daar, predicting that a combination of " $\mathrm{a}$

\section{FDA 'fails to keep track of transplant patients'}

[WASHINGTON] The US Food and Drug Administration (FDA) lacks an adequate means of locating tissue transplant recipients if donor tissue is discovered to be infected, according to the General Accounting Office (GAO), the investigative arm of Congress. And tighter regulations that the agency is proposing fail to address the problem adequately.

A report on human tissue banks issued by the GAO in December concludes that the FDA is seriously hindered in protecting public health because it has no register of the 400-or-so US tissue centres which process several hundred types of human tissues. Fewer than half of these centres are accredited by industry associations.

The FDA "can neither notify all tissue facilities as potential public health threats arise nor plan inspections from a complete registration of tissue facilities", says the report. In one typical case, researchers were unable to track the recipient of a tissue graft infected with hepatitis C.

The FDA has proposed a broad strengthening of its oversight of tissue transplantation, to be implemented slowly over coming years. It plans to require all tissue centres to register with the agency, and to report "adverse events". But the GAO report says that, in failing also to require centres to report "errors and accidents," the agency "is missing an opportunity to target facilities that may need additional oversight".

For instance, the FDA recently discovered while inspecting one company that it had distributed corneas before receiving test results showing that one cornea had tested positive for HIV. Under the agency's proposed plan, such an event would not have to be reported. Meredith Wadman perceived inadequate scientific base and negative publicity" would be likely to lead to a moratorium.

Strikingly different results from those of the NKF poll were obtained in the recent Eurobarometer poll of 15,000 people in the European Union, where support for xenotransplantation was assessed in the context of the acceptability of genetic engineering. More than three-quarters of respondents supported genetic engineering for the production of drugs and vaccines, but only 36 per cent thought xenotransplantation was morally acceptable and should be "encouraged", and the technology was considered the most risky of modern biotechnology applications (see Nature 387, 845; 1997).

The National Kidney Foundation has no position on xenotransplantation, according to Ellie Schlam, one of its officials. Schlam says the survey was carried out "so NKF could act as a catalyst to initiate a discussion among the American public". The report on the survey recommends targeting information campaigns at the clergy, who emerged from the poll as the profession with the most influence on the issue.

Most of those polled - including agnostics - said that endorsement of xenotransplantation research by religious leaders could make them agree to it. "In order to have them [clergy] making a positive, rather than negative, impact, they need to be fully informed... preferably before any public communication effort on xenotransplantation," recommends the report.

Louisa Chapman, an official at the US Centers for Disease Control in Atlanta, who has been involved in organizing consultation about imminent US guidelines on xenotransplantation, admits that the public lacks knowledge about the issue. "The debate has largely been in scientific, government and medical circles, but outside the communities working on those there is not much public awareness of the issues, which are mainly discussed in fairly obscure scientific literature, and commercial and research circles."

Indeed, organizations such as Friends of the Earth and the European Consumers' Association, which have been prominent in debates about the safety of genetically modified organisms, have not yet taken a position on xenotransplantation. Strong views on the subject in Britain, for example, tend to be confined to animal rights groups such as Compassion in World Farming.

"I'm very surprised by the nature of the public debate," says David Onions, a xenotransplantation researcher at the University of Glasgow. Onions describes the infectious disease risk as "a very serious matter", and adds: "I'm surprised it has not been more of an issue."

DeclanButler 